Published as: Superlattices Microstruct. 2012 June ; 51(6): 842-853.

\title{
Electrodeposition of $\mathrm{TiO}_{2}-\mathrm{RuO}_{2}-\mathrm{IrO}_{2}$ coating on titanium substrate
}

\author{
Mardali Yousefpoura,b,c, ${ }^{\star}$ and Amin shokuhy ${ }^{a}$ \\ Mardali Yousefpour: myousefpor@semnan.ac.ir \\ aMaterials Science and Engineering Department, University of Semnan, Semnan, Iran \\ bBio-Nano Materials Research Center, University of Semnan, Semnan, Iran \\ 'Nano Nafez Research Center, Semnan University Science and Technology Park, University of \\ Semnan, Semnan, Iran
}

\begin{abstract}
$\mathrm{TiO}_{2}, \mathrm{RuO}_{2}$, and $\mathrm{IrO}_{2}$ transition metal oxides have many applications in the field of applied electrochemistry. In this work, the mixed solid solutions of $\mathrm{TiO}_{2}-\mathrm{RuO}_{2}-\mathrm{IrO}_{2}$ coatings have been electrodeposited from aqueous-unaqueous baths.

Moreover, the obtained coatings have been heated in the electric furnace at $450{ }^{\circ} \mathrm{C}$. The microstructure of coating was characterized using scanning electron microscopy (SEM) and Atomic force microscopy (AFM). In order to investigate, the chemical composition and crystalline phases of coating, X-ray analysis, energy dispersive spectroscopy (EDS) were carried out. Furthermore, anodic polarization behavior of coating was investigated. Results show that heat treated coating at $450{ }^{\circ} \mathrm{C}$ with the chemical composition of $\mathrm{TiO}_{2} / \mathrm{RuO}_{2} / \mathrm{IrO}_{2}$ with molar ratio of $70 / 5 / 25$ with six layer on substrate has the highest quality, stability, adhesion strength and minimum chlorine overvoltage. However, increasing the iridium content in electrolyte enhances the coating thickness and the quality of morphology.
\end{abstract}

\section{Keywords}

Scanning electron microscopy; Coating; Microstructure; X-ray analysis; Adhesion; Titanium substrate; Mixed solid solution

\section{Introduction}

Ruthenium oxide $\left(\mathrm{RuO}_{2}\right)$, Titanium oxide and Iridium oxide with Rutile structure, are of increasing interest because of the unusual and unique properties [1,2]. Titanium electrodes coated with the mixed solid solutions of $\mathrm{RuO}_{2}-\mathrm{IrO}_{2}-\mathrm{TiO}_{2}$ are more attractive in the chloralkali industry as dimensional stable anodes (DSA) [3,4], which were considered as one of the most important discovery in electrochemical field in the 20th Century. Then they have

(C) 2012 Elsevier Ltd. All rights reserved.

*Corresponding author at: Materials Science and Engineering Department, University of Semnan, Semnan, Iran. Tel: +98 2313366385 ; fax: +98 2313354119. 
found widespread applications in recent years, due to their excellent catalytic properties for the chlorine and oxygen evolution reaction [5,6]. Also, they are interesting electrode materials for application in organic electrooxidation, and have stimulated activity in the field of wastewater treatments [7,8]. Moreover, there are good perspective application of these metal oxide coated electrodes as supercapacitors [9].

In recent years an interesting group of catalysts depending on the oxides of noble metals of ruthenium and iridium, were reported [10]. $\mathrm{RuO}_{2}$ is particularly interesting because of its excellent electro-catalyst properties [11], where $\mathrm{IrO}_{2}$ is more stable and has the longer service life time [12]. In order to improve the electrocatalyst behavior and the electrode stability, the mixed-oxide of $\mathrm{RuO}_{2} / \mathrm{IrO}_{2}[13], \mathrm{RuO}_{2} / \mathrm{TiO}_{2}$, and $\mathrm{IrO}_{2} / \mathrm{TiO}_{2}$ have been studied, $[14,15]$. Moreover, to produce oxide coated electrodes for specific applications, different synthetic methods, e.g., chemical vapor deposition (CVD), hydro-thermal synthesis, electrodeposition, sol-gel, and sputtering, have been investigated, [16-19]. But, ternary oxide coatings of titanium, ruthenium and iridium on titanium substrate have not been investigated by an electrodeposition method. In this case, electrodeposition technique was used to produced the mixed solid solution of $\mathrm{RuO}_{2}-\mathrm{IrO}_{2}-\mathrm{TiO}_{2}$ coating on titanium substrate. In this method, metal ions can be hydrolyzed by an electrogenerated to form hydroxide films on the cathodic substrate. Oxide films are obtained by the thermal dehydration of hydroxides [20,21].

This paper presents, for the first time, an investigation of the feasibility of forming the ternary oxide coatings of titanium, ruthenium and iridium on titanium substrate via electrodeposition as a new method.

\section{Experimental procedures}

A one-compartment three-electrode electrochemical cell included of Pyrex glass was used. The working electrode was a Pt. The mixed solid solution of $\mathrm{RuO}_{2}-\mathrm{IrO}_{2}-\mathrm{TiO}_{2}$ coating on titanium substrate was prepared by the cathodic electrodeposition. The precursor solution made of $\mathrm{TiCl}_{4}$ (Merck), $\mathrm{RuCl}_{3} \cdot \mathrm{nH}_{2} \mathrm{O}$ (Merck), $\mathrm{IrCl}_{3} \cdot \mathrm{nH}_{2} \mathrm{O}$ (Merck) and hydrogen peroxide $\mathrm{H}_{2} \mathrm{O}_{2}$ (30 wt.\% in water, Merck), and methanol in the molar ratio of 70:15:15, 70:5:25, and 70:25:5 of $\mathrm{TiO}_{2}: \mathrm{RuO}_{2}: \mathrm{IrO}_{2}$. This precursor solution was coated onto the titanium substrate (geometric area $=0.1 \mathrm{~cm}^{2}$ ) by an electrodeposition route. The deposition bath temperature was kept at $1{ }^{\circ} \mathrm{C}$. Cathodic deposit was obtained at a constant current density of $20 \mathrm{~mA} / \mathrm{cm}^{2}$ for $20 \mathrm{~min}$. In order to decrease the cracks attributed to drying shrinkage, cathodic deposit was carried out the layer by layer. The obtained deposits were washed with water in order to remove $\mathrm{Cl}$ ions and inorganic solvent and then dried in the air. Heat treatment was carried out in an electerical furnace at temperature of $450{ }^{\circ} \mathrm{C}$ with a heating rate of $10{ }^{\circ} \mathrm{C} / \mathrm{min}$ for 20 $\min$.

The crystallinity of the coatings was evaluated by X-ray diffraction analysis (XRD) (Bruker diffractometer, model D4), using CuKa radiation with $\left.1.5406^{\circ} \mathrm{A}\right)$. The microstructure and semi-quantity chemical composition of the coating was studied using a scanning electron microscope (MEGA/TESCAN), and the Energy Dispersive Spectroscopy (EDS). In order to 
investigate the more details of the morphology, atomic force microscopy (Dualscop/ Rasterscop C26, DME) was done under the contact mode.

Anodic behavior of coated samples was studied in a conventional three electrode cells system. A platinum electrode was used as the counter electrode and a saturated calomel electrode (SCE) as the reference electrode. Anodic polarization curves have been obtained at a scan rate of $5 \mathrm{mVs}^{-1} \mathrm{SCE}$ in a solution of $300 \mathrm{gr} . \mathrm{l}^{-1}$ of $\mathrm{NaCl}$ at temperature of $87{ }^{\circ} \mathrm{C}$ with EG\&G system. Life time curves have been carried out using a galvano state system at 1.2 $\mathrm{A} / \mathrm{cm}^{2}$ and potential range of $30-40 \mathrm{~V}$ in solution of $0.3 \mathrm{M}$ of $\mathrm{NaCl}$ in water.

\section{Results and discussion}

The electrodeposition of $\mathrm{TiO}_{2}, \mathrm{RuO}_{2}$, and $\mathrm{IrO}_{2}$ have been carried out onto Ti substrate from aqueous solution bath under certain conditions. The effect of number of coating on the morphology, polarization behavior and life time are described as follows.

\subsection{The effect of number of coatings on the morphology}

3.1.1. One layer coating-Fig. 1 shows an $\mathrm{SEM}$ micrograph of the $\mathrm{TiO}_{2}-\mathrm{RuO}_{2}-\mathrm{IrO}_{2}$ coating with one layer, which presents the large microcracks on the surface of coating. Fig. $1 \mathrm{a}$ and $\mathrm{b}$ show, that the size of grains reduce and the propagation of microcracks into the grains is limited. Also, the microcracks width get a small value. But, as it is seen in Fig. 1c, that grains size get a coarse value again. It can be concluded that by reducing $\mathrm{RuO}_{2}$ and increasing $\mathrm{IrO}_{2}$ weight percent in the coating, a more compact microstructure is produced. Also, the grain size is got a small value and the presence of the microcracks is limited. The presence of the microcracks can be attributed to the thermal expansion differences among $\mathrm{TiO}_{2}, \mathrm{RuO}_{2}, \mathrm{IrO}_{2}$, and the thickness of coating.

In Fig. 2 the XRD pattern for the ternary oxide coating with one layer on Ti substrate is presented. The main peaks for the $\mathrm{TiO}_{2}, \mathrm{RuO}_{2}, \mathrm{IrO}_{2}$ phases, and the respective peak for the titanium surface are observed. It can be confirmed that $\mathrm{TiO}_{2}, \mathrm{RuO}_{2}$, and $\mathrm{IrO}_{2}$ phases are formed by an electrodeposition process.

Fig. 3 shows the EDS profiles of the corresponding micrographs in Fig. 1, that are marked with point $\mathrm{P}$. The XRD results is confirmed by EDS results. Therefore, it can be seen that the main peaks of $\mathrm{TiO}_{2}, \mathrm{RuO}_{2}$, and $\mathrm{IrO}_{2}$, are formed in the coating via electrodeposition method. The chemical composition of the coating is listed in Table 1 as well as. It is concluded that the four major elements of $\mathrm{Ti}, \mathrm{Ru}$, Ir and $\mathrm{O}$ are presented on the surface of coating on Ti substrate. Also, the absence of $\mathrm{H}$ element is a reason that the evaporation of alcoholic solvent from the surface coating is completed. On the other hand, Table 1, reports that the atomic percent of oxygen is the lowest amount of 51.99 and the maximum of the atomic percent of oxygen is related to the chemical composition with the molar ratio of 70:5:25 of $\mathrm{TiO}_{2}-\mathrm{RuO}_{2}-\mathrm{IrO}_{2}$ with the highest amount of Ir at.\%.

3.1.2. Four layers coating-Fig. 4 shows the microstructure of the four layer of coating with the ternary oxides on Ti substrate. It can be seen that by increasing the number of coating from one to four layer, the coating morphology converts to agglomerated state. The 
reason is ascribed to the fact that the coating in every layer is precipitated over the prior layer. Then, the microcracks are clear in Fig. 4a-c.

Fig. $4 \mathrm{c}$ shows the wider cracks that are formed inside the grains. But, the microcracks produced are much smaller, that are presented in Fig. 4b. Therefore it can be resulted that by increasing the Ir amount in the ternary oxide coating, the formation of the microcracks is prevented, and is improved the uniform morphology. Then, a coating with high corrosion resistance is produced.

The AFM images that obtained from the coating with one layer are seen in Fig. 5. Fig. 5b, shows the higher roughness on the surface of coating with chemical composition of 70:5:15 than the coating with chemical composition of 70:15:15, and 70:25:5. As a result, by increasing the amount of $\mathrm{IrO} 2$ in the coating, the roughness of surface of coating will be increased.

Fig. 6 shows the XRD patterns of the ternary oxide coating with four layer on Ti. Similar to the results in Fig. 2. The main peaks of $\mathrm{TiO}_{2}$ and $\mathrm{RuO}_{2}$ and $\mathrm{IrO}_{2}$ are cleared in the coating. EDS results of that coating are observed in Fig. 7. Point p in Fig. 4 is used to EDS analysis. The main elements of coating are listed in Table 2. It is seen the principle elements are available. Results show that increasing the amount of Ru and Ir causes an increasing of the amount of these elements in the coating. In four layer of coating with compared to one layer of coating, Iridium amount is higher than Ruthenium. Also, it is resulted that the increasing the $\mathrm{Ru}$ amount in the coating causes the microcracks and changes the morphology.

3.1.3. Six layers coating-Fig. 8 shows SEM results of coating with six layers on Ti. The results show that the coating in this step has a substantially different morphology with compared to the above mentioned steps. It is observed that the microcracks are at least amount, but are not presented. Then it is worthy to explain that the best morphology is related to the six layers of coating, Fig. 8c. Fig. 9 shows the AFM images obtained from the coating. Fig. 9c shows the higher roughness than roughness in Fig. 9a and b.

On the other hand, the microcracks formation is limited in six layers of coating. and they are not observed in this step. Also, the roughness of the surface of coating is increased.

The presences of main peaks of $\mathrm{TiO}_{2}, \mathrm{RuO}_{2}$, and $\mathrm{IrO}_{2}$ in the coating are seen in Fig. 10, which shows the XRD patterns of the ternary oxide coatings in the six layers of coating on Ti. In order to confirm the above results, EDS analysis was carried out on surface of coating. The obtained results are presented in Fig. 11. The presence of elements in the coating is listed in Table 3. This table shows the principle elements are available.

\subsection{Investigation of polarization}

The potentiodynamic polarization curves of Ti coated with the ternary oxide after six layer of coating are shown in Fig. 12. It is observed that increasing the amount of $\mathrm{IrO}_{2}$ in the chemical composition of coating decreases the chlorine over voltage. Thus, slope of the polarization curve declines. Also the smooth slope of the polarization curve can be related to the higher adhesion strength. Therefore, the life time of coating is improved because of the 
decreasing of the failure of coating. Consequently more decreasing the slope of the polarization curve is related to higher amount of $\mathrm{IrO}_{2}$. Then it can be seemed that this coating has the optimal chemical composition.

\subsection{The life time of coating}

Fig. 13 shows the results of life time curves of the ternary oxide coatings on Ti with the coating produced of six layers. As it is seen in Fig. 13a, it can be seen that the slope of the potential curve is low at the early times and it increases slightly via time. When the applied potential time is not enough to form $\mathrm{TiO}_{2}$ in the interface of titanium and coating, increasing the potential will not be sudden. Thus the coating will resist against the corrosive solution. Also, if the coating has enough adhesion to the titanium substrate due to increasing the amount of $\mathrm{IrO}_{2}$, it will resist to breakdown.

Fig. 13b shows the increasing of potential is gradually again. $\mathrm{But} \mathrm{TiO}_{2}$ has not been formed in the interface of substrate and coating. Then the coating has not been breakdown. Actually, six layer of coating has a good adhesion after $1 \mathrm{~h}$ heating in the temperature of $450{ }^{\circ} \mathrm{C}$ and will oppose to breakdown. In Fig. $13 \mathrm{c}$ the potential increases gradually and meanwhile the coating dissolves homogenously. Then $\mathrm{TiO}_{2}$ can be formed little by little in the interface of titanium and the coating. This behavior is induced that the increasing of potential is gradually. As a result the increasing of potential can be caused failure the coating.

\section{Conclusion}

The aim of the present work was to investigate the feasibility of forming the ternary oxide coating including titanium, ruthenium and iridium oxides on the titanium substrate by an electrodeposition technique. The following results were taken:

1. The variation of electrolyte composition has a significant effect on the coating surface morphology.

2. It was shown that the $\mathrm{TiO}_{2}, \mathrm{RuO}_{2}$, and $\mathrm{IrO}_{2}$ phases are formed via the electrodeposition technique.

3. The more uniformity in morphology of the coating is obtained when the Ir at.\% is higher than Ru.

4. The optimal compositions of $\mathrm{TiO}_{2} / \mathrm{RuO}_{2} / \mathrm{IrO}_{2}$ with molar ratio of $70 / 5 / 25$ is suggested based on the investigations. Also, it supposed that the coating with six layers is the useful coating. It means that by increasing the number of coatings the inhomogeneity and porosity on the surface disappears, crystal grains will be refined, and the homogenous morphology will be formed. On the other hand, by increasing the $\mathrm{IrO}_{2}$ content in the coating composition the density of the grains increases and they get smaller values in size while the cracks get narrower.

5. The polarization investigations clarified that by increasing the layer numbers of coating and $\mathrm{IrO}_{2}$ content, the over voltage will be decreased.

6. The galvanostatic investigations showed that the increasing $\mathrm{IrO}_{2}$ content of the coating causes the failure of the coating after $1 \mathrm{~h}$ in a $0.3 \mathrm{M}$ solution of $\mathrm{NaCl}$ in 
water under applying a DC current of $1.2 \mathrm{~A} / \mathrm{cm}^{2}$ in potential range of $30-40 \mathrm{~V}$. However the coating with six layers and the chemical composition of $\mathrm{TiO}_{2} /$ $\mathrm{RuO}_{2} / \mathrm{IrO}_{2}$ with molar ratio of $70 / 5 / 25$ under the same condition resists to the failure.

\section{Acknowledgments}

Authors gratefully thank University of Semnan, bio-nano-materials research center and the nano nafez company in the Semnan University Science and Technology Park for partially supporting the research.

\section{References}

1. Trasatti, S. Interfacial Electrochemistry: Theory, Experiment and Applications. Wieckowski, A., editor. Marcel Dekker; New York: 1999.

2. Park BO, Lokhande CD, Park HS, Jung KD, Joo OS. Cathodic electrodeposition of $\mathrm{RuO}_{2}$ thin films from $\mathrm{Ru}(\mathrm{III}) \mathrm{Cl}_{3}$ solution. Mater Chem Phys. 2004; 87(1):59.

3. Hutchings R, Müller K, Kötz R, Stucki S. A structural investigation of stabilized oxygen evolution catalysts. J Mater Sci. 1984; 19:3987.

4. Guglielmi M, Colombo P, Rigato V, Battaglin V, Debattisti A. Compositional and microstructural characterization of $\mathrm{RuO}_{2}-\mathrm{TiO}_{2}$ catalysts synthesized by the sol-gel method. J Electrochem Soc. 1992; 139(6):1655.

5. Santos MRG, Goulart MOF, Tonholo J, Zanta CLPS. The application of electrochemical technology to the remediation of oily wastewater. Chemosphere. 2006; 64:393. [PubMed: 16473394]

6. Ferro S, Donatoni M, Battist AD, Andreev VN. Adsorption of thallium cations on RuO-TiO electrodes. J Appl Electrochem. 2007; 37:1389.

7. Ma H, Liu C, Liao J, Su Y, Xue X, Xing W. Study of ruthenium oxide catalyst for electrocatalytic performance in oxygen evolution. J Mol Catal A. 2006; 247:7.

8. Barison S, Battisti AD, Fabrizio M, Daolio S, Piccirillo C. Surf. Chem. of $\mathrm{RuO}_{2} / \mathrm{IrO}_{2} / \mathrm{TiO}_{2}$ mixedoxide electrodes: secondary ion mass spectrometric study of the changes induced by electrochemical treatment. Rapid Commun Mass Spectrom. 2000; 14(23):2165. [PubMed: 11114026]

9. Battaglin G, Rigato V, Zandolin S, Benedetti A, Ferro S, Nanni L, De Battisti A. Microstructural characterization and electrochemical properties of $\mathrm{RuO}_{2}$ thin film electrodes prepared by reactive radio-frequency magnetron sputtering. Chem Mater. 2004; 16(5):946.

10. Yi Z, Kangning C, Wang WJ, Lee $\mathrm{S}$. Effect of $\mathrm{IrO}_{2}$ loading on $\mathrm{RuO}_{2}-\mathrm{IrO}_{2}-\mathrm{TiO}_{2}$ anodes: A study of microstructure and working life for the chlorine evolution reaction. Ceram Int. 2007; 33:1087.

11. Patake VD, Lokhande CD, Joo OS. Electrodeposited ruthenium oxide thin films for supercapacitor: effect of surface treatments. Appl Surf Sci. 2009; 255(17):4192.

12. De Pauli CP, Trasatti S. Composite materials for lectrocatalysis of $\mathrm{O}_{2}$ evolution: $\mathrm{IrO}_{2} / \mathrm{SnO}_{2}$ in acid solution. J Electroanal Chem. 2002; 538:145.

13. Trasatti S. Electrocatalysis: understanding the success of DSA. Electrochem Acta. 45(2000):2377.

14. De Battisti A, Brina R, Gavelli G, Benedetti A, Fagherazzi GJ. J Electroanal Chem. 1986; 200:93.

15. De Battisti A, Lodi G, Cappadonia M, Battaglin G, Kötz R. J Electrochem Soc. 1989; 136:2597.

16. Zhang Y, Wang C, Wan N, Mao Z. Deposited RuO2-IrO2/Pt electrocatalyst for the regenerative fuel cell. Int J Hydrogen Energy. 2007; 32:400.

17. Kovtyukhova NI, Mallouk TE. Electrochemically assisted deposition as a new route to transparent conductive indium tinoxide films. Chem Mater. 2010; 22:4939.

18. Xin W, Zhi TZ, Dian T. Crystal growth kinetics and size ols - I for some anode active oxides. Chin J Struct Chem. 2010; 29(6):972.

19. Wang C, Yin L, Zhang L, Xiang D, Gao R. Metal oxide gas sensors: sensitivity and influencing factors. Sensors. 2010; 10:2088. [PubMed: 22294916] 
20. lazic M, Simovic K, Miskovic-Stankovic V, Jovanic P, Kicevic D. The influence of the deposition parameters on the porosity of thin alumina films on steel. J Serb Chem Soc. 2004; 69(3):239.

21. Zhitomirsky I. Electrodeposition of lanthanum hydroxide-polyethylenimine films. Mater Lett. 2003; 57:3761. 

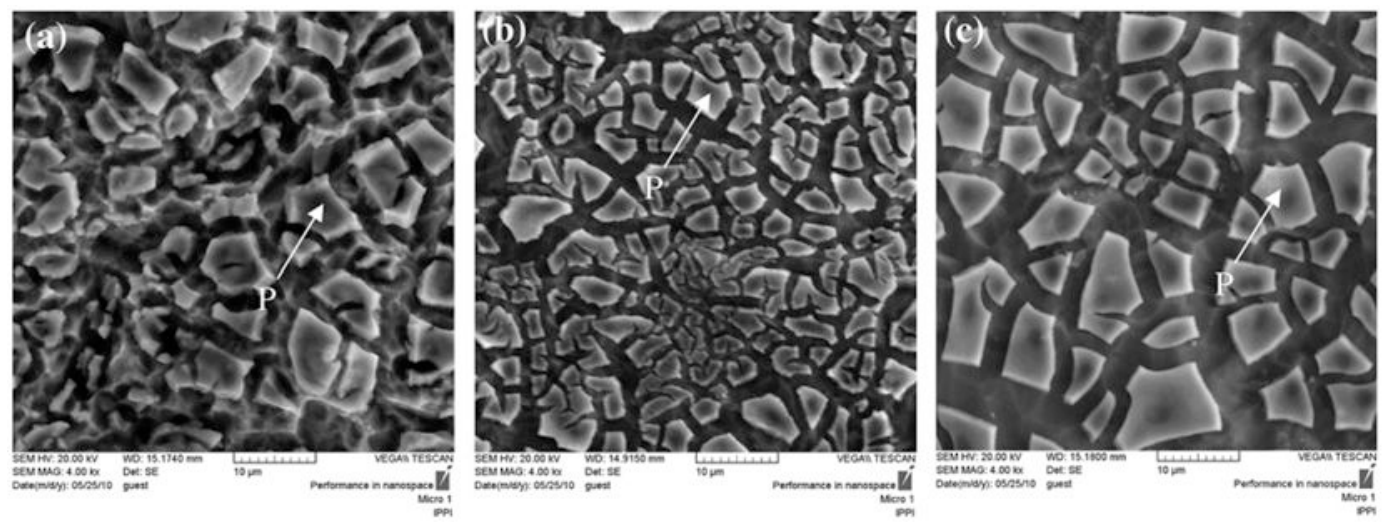

Fig. 1.

SEM micrographs of Ti coated with one layer of coating with chemical composition of (a) $70: 15: 15$, (b) 70:5:25, and (c) 70:25:5 of $\mathrm{TiO}_{2}: \mathrm{RuO}_{2}: \mathrm{IrO}_{2}$. 


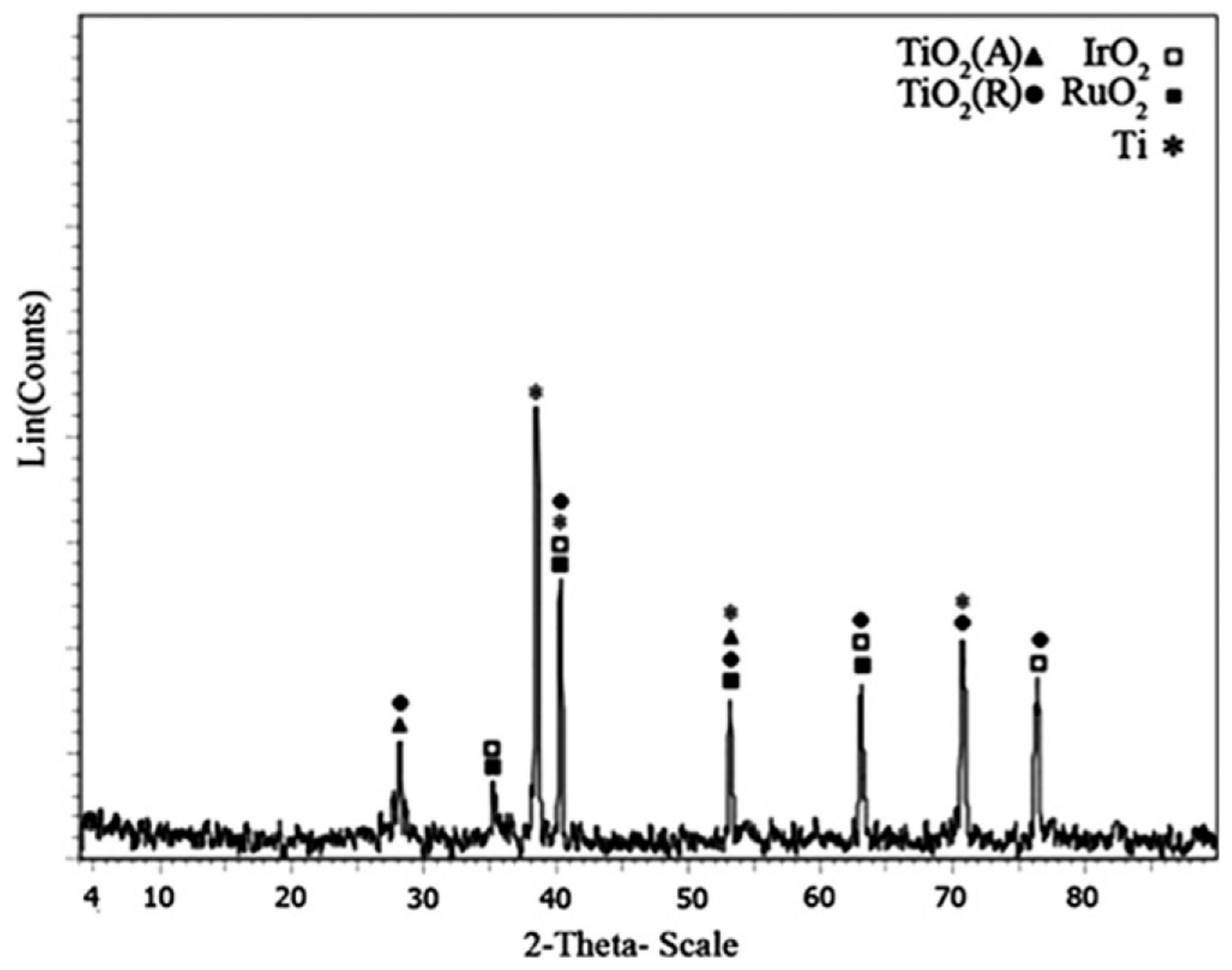

Fig. 2.

XRD Patterns of Ti coated with on layer of coating with chemical composition of 70:15:15 of $\mathrm{TiO}_{2}: \mathrm{RuO}_{2}: \mathrm{IrO}_{2}$. 

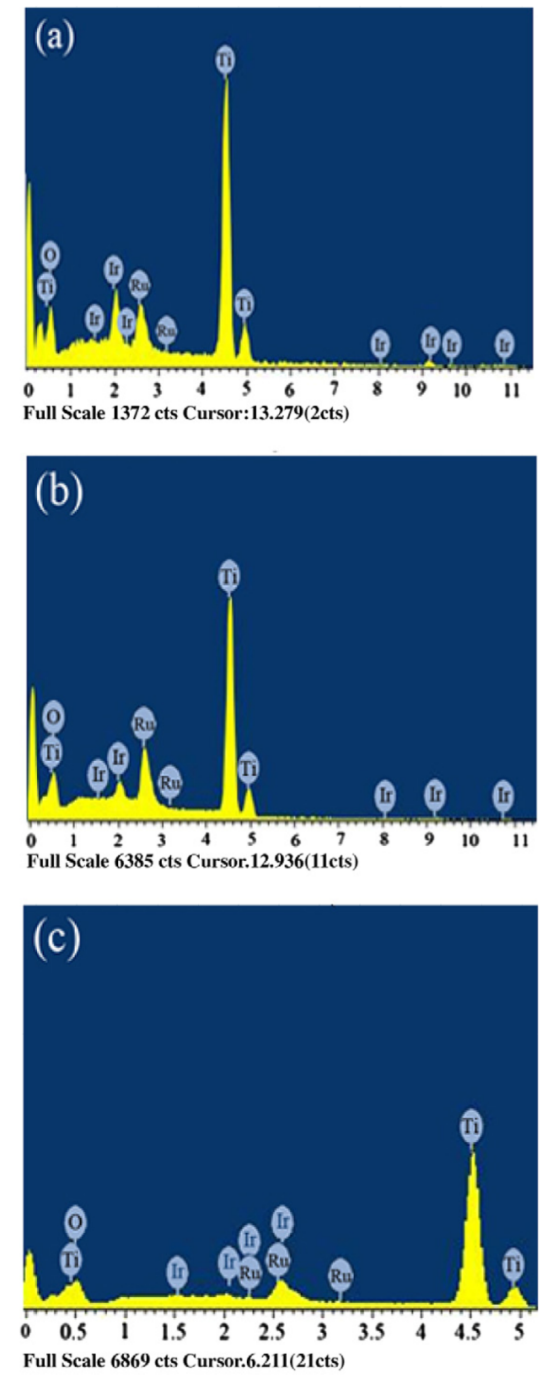

Fig. 3.

EDS profiles of the corresponding point in Fig. 1 after one layer of coating with chemical composition of (a) 70:15:15, (b) 70:5:25, and (c) 70:25:5 of $\mathrm{TiO}_{2}: \mathrm{RuO}_{2}: \mathrm{IrO}_{2}$. 

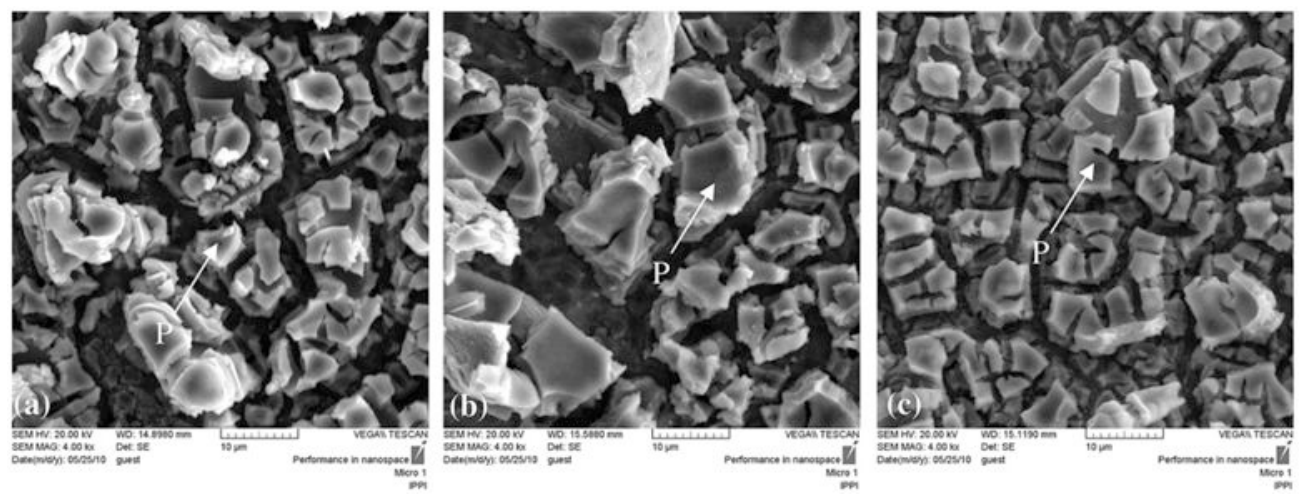

Fig. 4.

SEM micrographs of Ti coated with four layer of coating with chemical composition of (a) 70:15:15, (b) 70:5:25, and (c) 70:25:5 of $\mathrm{TiO}_{2}: \mathrm{RuO}_{2}: \mathrm{IrO}_{2}$. 


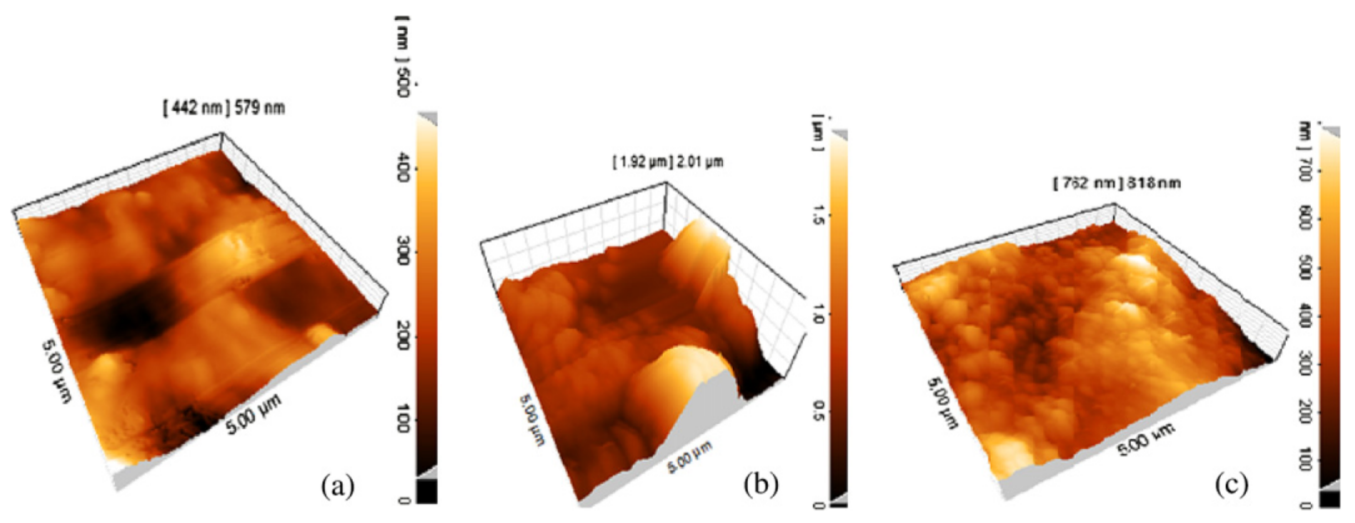

Fig. 5.

AFM images of Ti coated with four layer of coating with chemical composition of (a) 70:15:15, (b) 70:5:25, and (c) 70:25:5 of $\mathrm{TiO}_{2}: \mathrm{RuO}_{2}: \mathrm{IrO}_{2}$. 


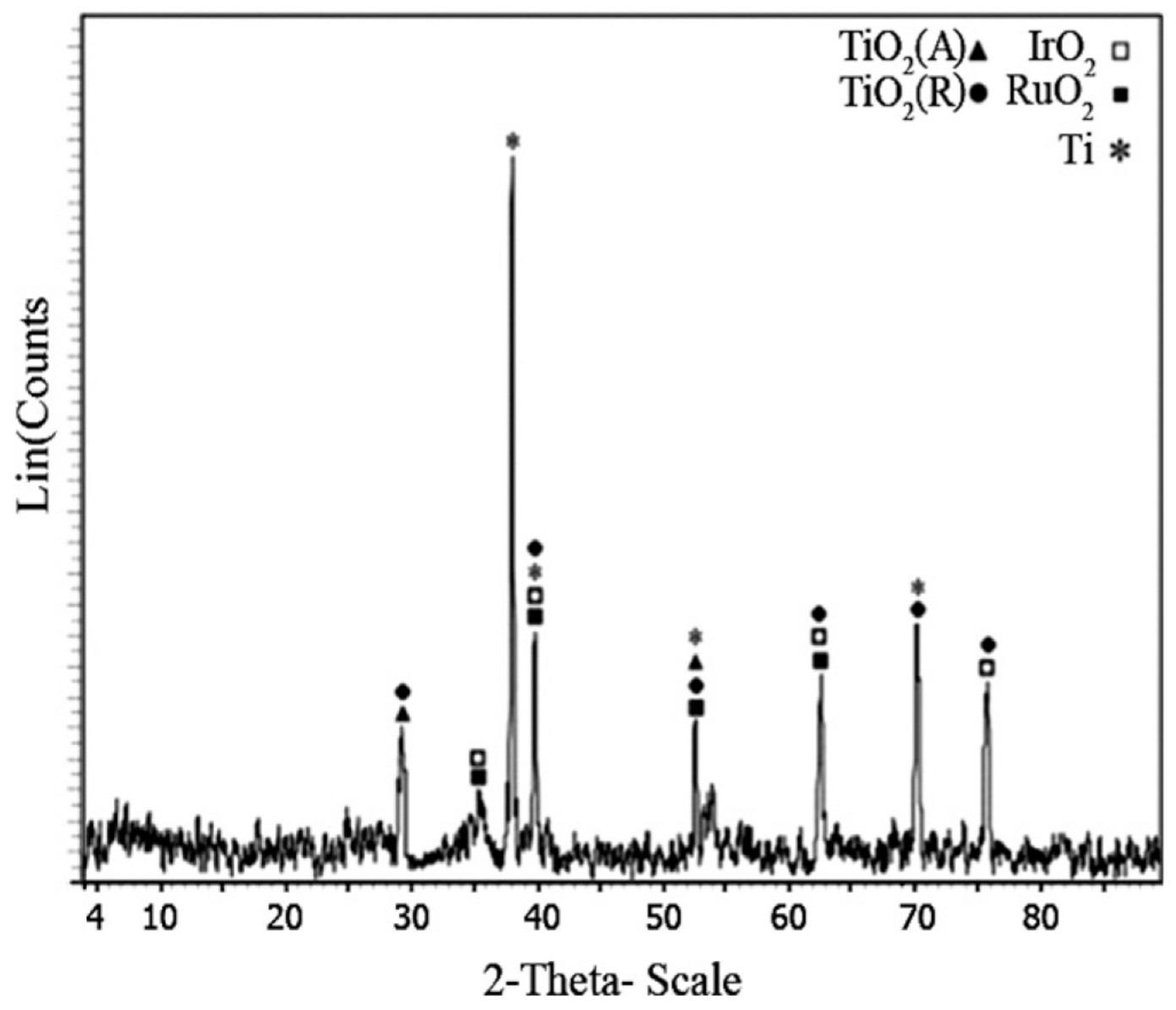

Fig. 6.

XRD Patterns of Ti coated with four layer of coating with chemical composition of 70:15:15 of $\mathrm{TiO}_{2}: \mathrm{RuO}_{2}: \mathrm{IrO}_{2}$. 

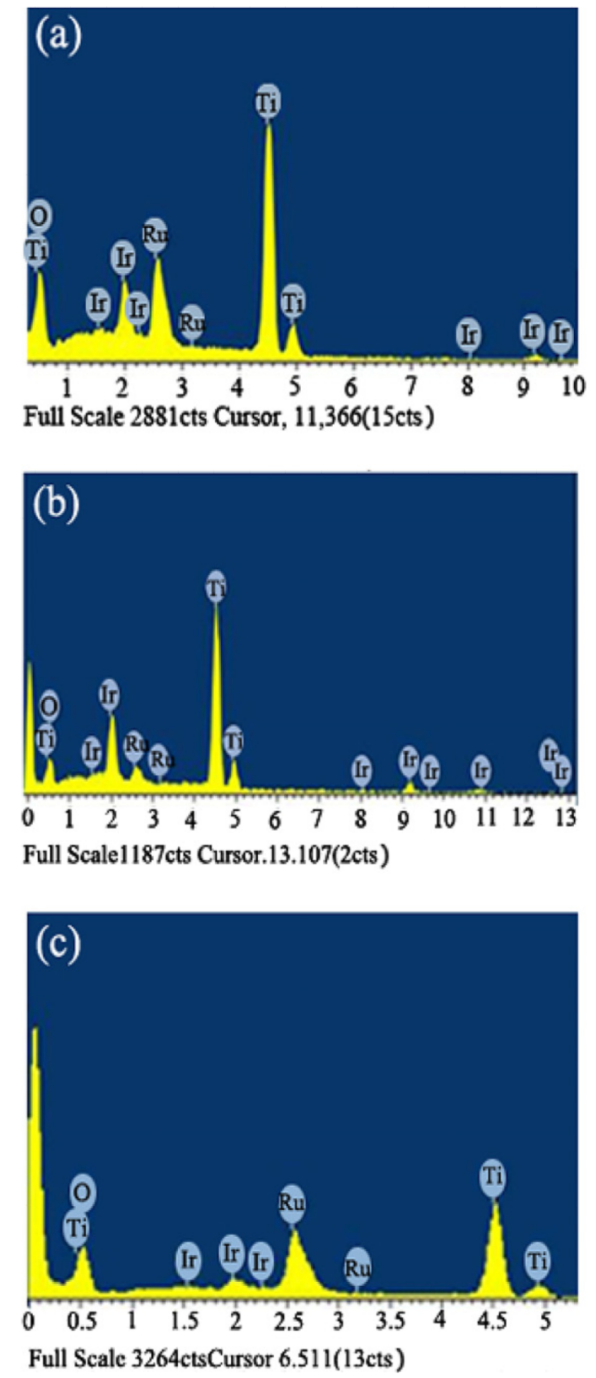

Fig. 7.

EDS profiles of the corresponding point in Fig. 1 after four layers of coating with chemical composition of (a) 70:15:15, (b) 70:5:25, and (c) 70:25:5 of $\mathrm{TiO}_{2}: \mathrm{RuO}_{2}: \mathrm{IrO}_{2}$. 

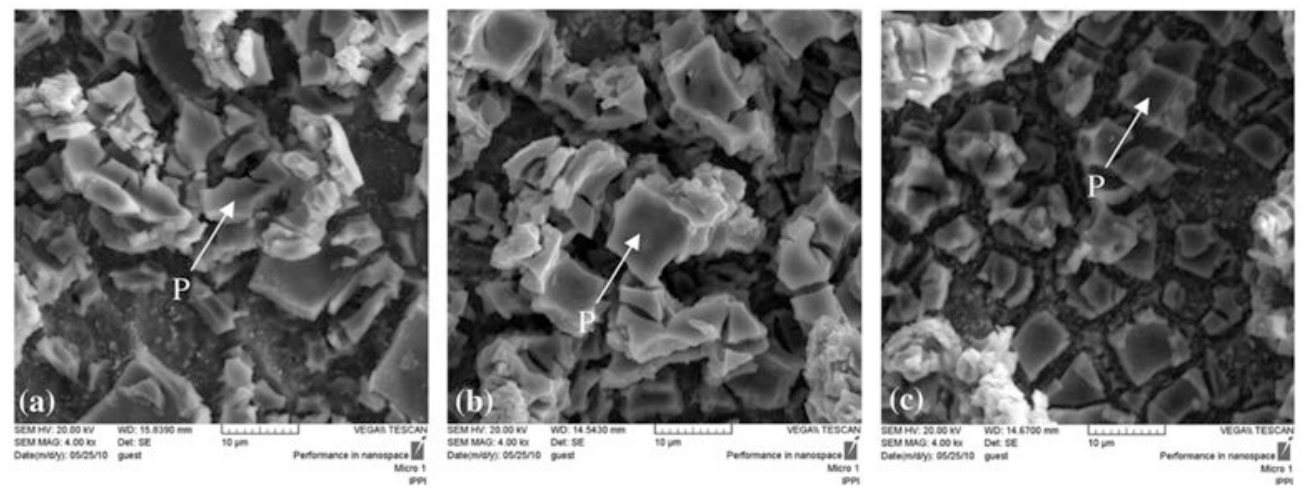

Fig. 8.

SEM micrographs of Ti coated after six layers of coating with chemical composition of (a) 70:15:15, (b) 70:5:25, and (c) 70:25:5 of $\mathrm{TiO}_{2}: \mathrm{RuO}_{2}: \mathrm{IrO}_{2}$. 


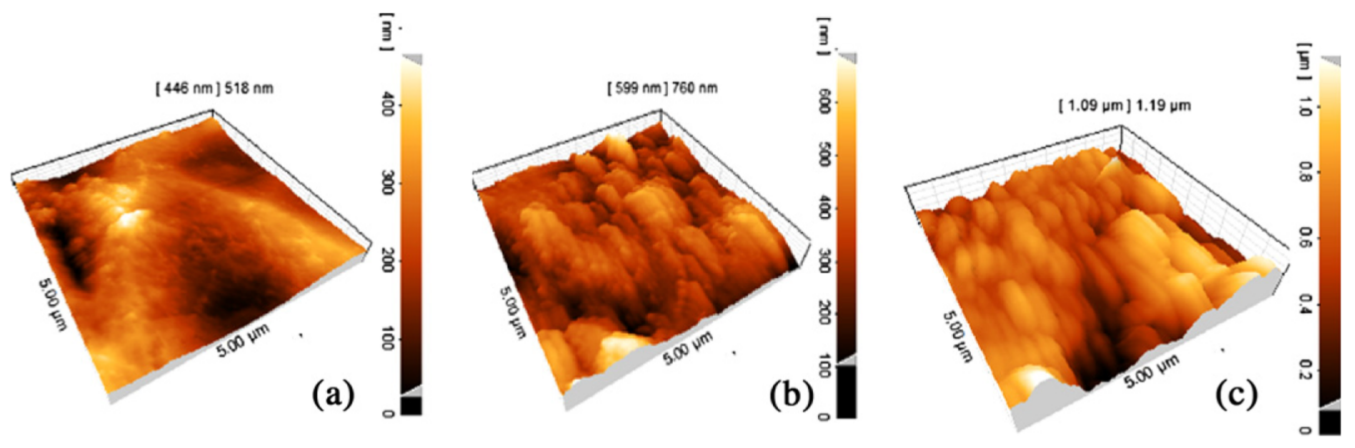

Fig. 9.

AFM images of Ti coated after six layers of coating with chemical composition of (a) 70:15:15, (b) 70:25:5, and (c) 70:5:25 of $\mathrm{TiO}_{2}: \mathrm{RuO}_{2}: \mathrm{IrO}_{2}$. 


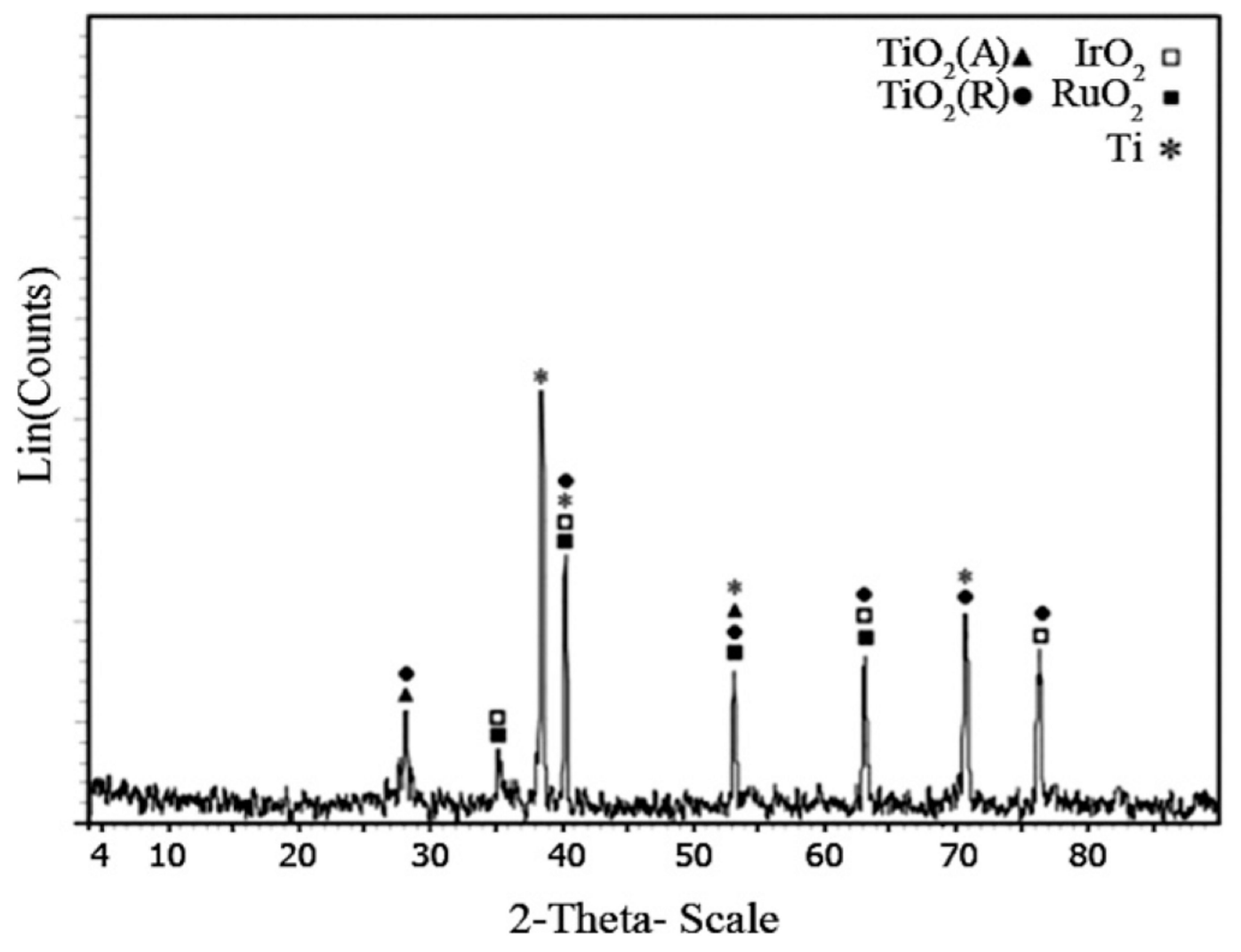

Fig. 10.

XRD Patterns of Ti coated XRD Patterns of Ti coated after six layer of coating with chemical composition of 70:15:15 of $\mathrm{TiO}_{2}: \mathrm{RuO}_{2}: \mathrm{IrO}_{2}$. 

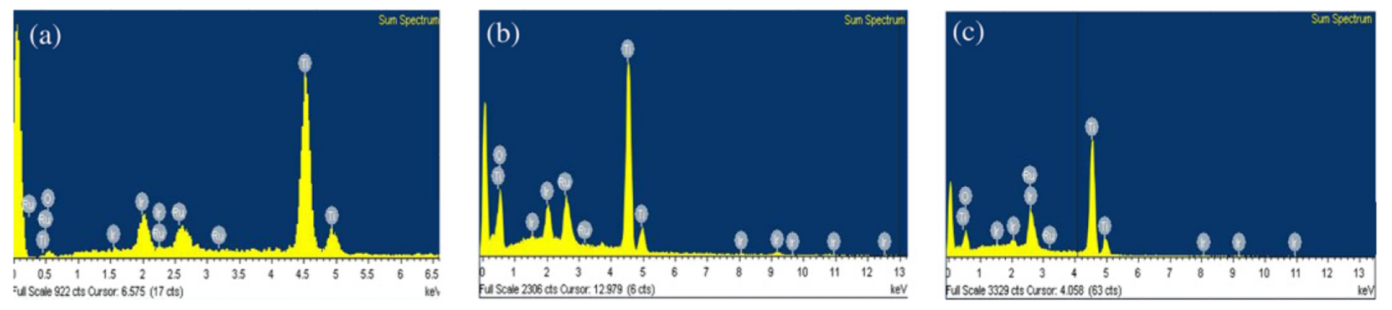

Fig. 11.

EDS profiles of the corresponding point in Fig. 1 after six layers of coating with chemical composition of (a) 70:15:15, (b) 70:5:25, and (c) 70:25:5 of $\mathrm{TiO}_{2}: \mathrm{RuO}_{2}: \mathrm{IrO}_{2}$. 

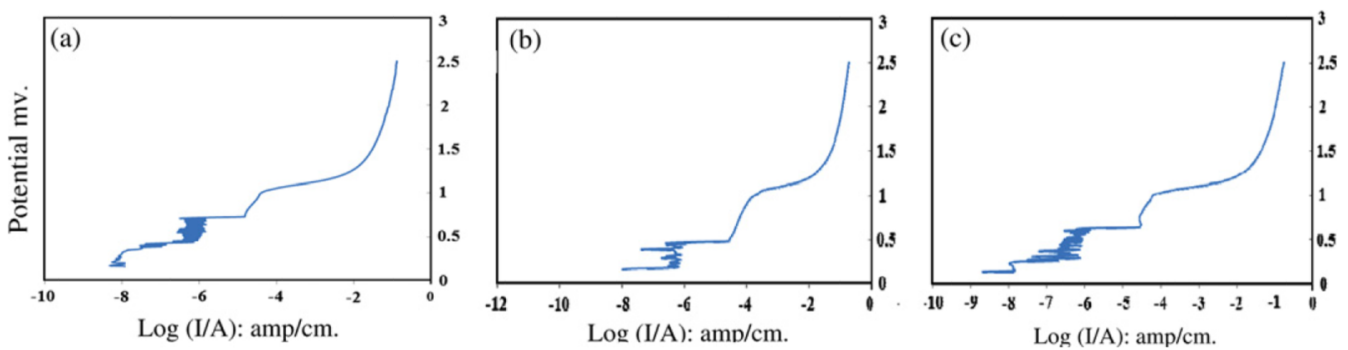

Fig. 12.

Polarization curves of Ti coated after six layers of coating with chemical composition of (a) $70: 15: 15$, (b) 70:5:25, and (c) 70:25:5 of $\mathrm{TiO}_{2}: \mathrm{RuO}_{2}: \mathrm{IrO}_{2}$. 

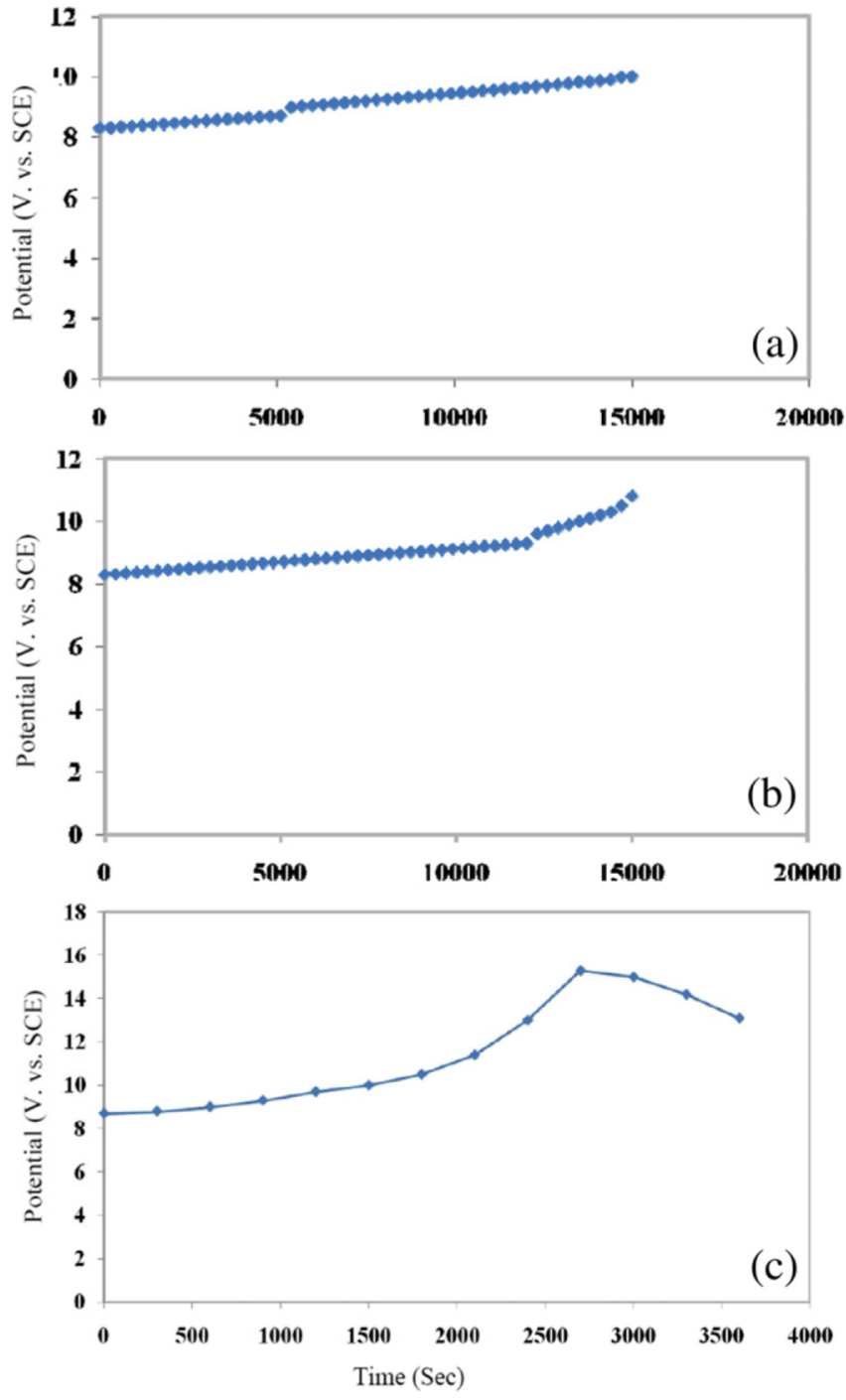

Fig. 13.

Failure curves of Ti coated after six layers of coating with chemical composition of (a) $70: 15: 15$, (b) 70:5:25, and (c) 70:25:5 of $\mathrm{TiO}_{2}: \mathrm{RuO}_{2}: \mathrm{IrO}_{2}$. 
$\frac{5}{\circ}$

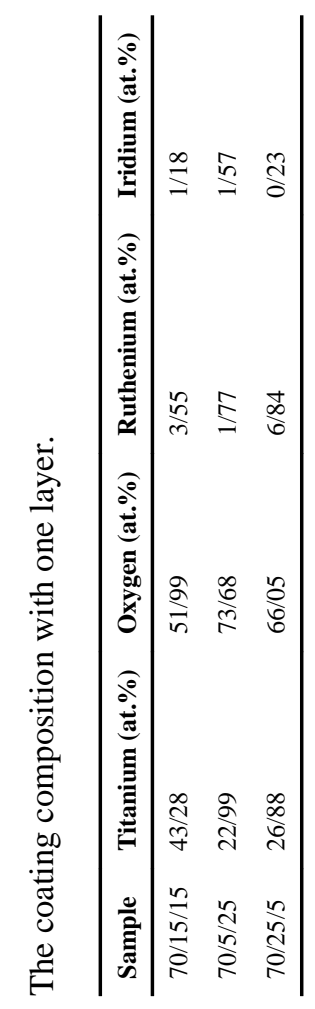

Superlattices Microstruct. Author manuscript; available in PMC 2014 September 28. 


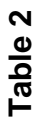

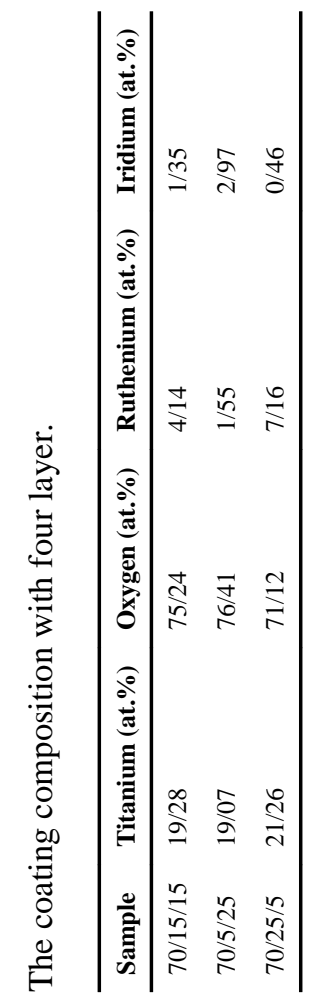

Superlattices Microstruct. Author manuscript; available in PMC 2014 September 28. 
0
$\frac{1}{0}$
$\frac{10}{1}$

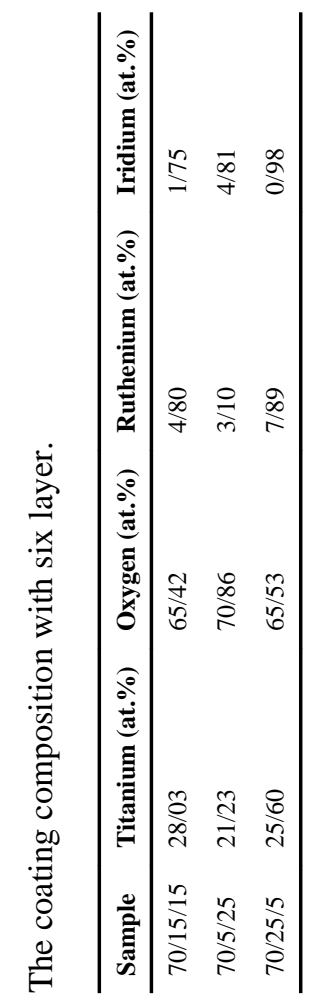

Superlattices Microstruct. Author manuscript; available in PMC 2014 September 28. 